\title{
HACIA LA CREACIÓN DE LA CORTE INTERNACIONAL DE JUSTICIA AMBIENTAL
}

\section{Mercedes Amanda Cóndor Salazar"}

\author{
Recibido: Diciembre 21 de 2016 \\ Aprobado: Marzo 7 de 2017

\section{RESUMEN}

La idea central del presente artículo gira en torno a que el Derecho Internacional Público desde una visión pragmática responde netamente a una retórica para justificar las acciones políticas de los Estados pero desde una visión idealista también responde a concepciones más abstractas como la búsqueda de la paz y la protección al medio ambiente. En definitiva el Derecho Internacional Público se debate en un delicado equilibrio entre el realismo y el idealismo y la propuesta del Estado Ecuatoriano de creación de la Corte Internacional de Justicia Ambiental, es una propuesta eminentemente idealista.

Palabras clave: Naturaleza, ambiente, ecocidio, Derecho Internacional Público, Corte Penal Internacional, Derecho Penal Internacional.

\section{TOWARDS THE CREATION OF THE INTERNATIONAL ENVIRONMENTAL COURT}

\begin{abstract}
The main idea of this article refers to the fact that from a pragmatic vision, Public International Law responds clearly to a rhetorical strategy in order to justify political actions of the States, but from an idealistic vision it also responds to abstract conceptions in search of peace and

* Abogada (PUCE-Ecuador), Estudiante regular del programa de doctorado en Derecho Constitucional (PHD) Universidad de Buenos Aires (Argentina); Magíster en Gobernanza y Ciencias Políticas, Universidad George Washington (Estados Unidos) (e), Magister y Especialista Superior en Derecho Procesal, Universidad Andina Simón Bolívar. Actualmente Presidenta de la firma jurídica Advocate S.A. Ex Asesora Jurídica de la Asamblea Nacional, Corte Constitucional, Ministerio de Justicia y Derechos Humanos y Defensoría del Pueblo del Ecuador. Correo electrónico mercedescondor@gmail.com.
\end{abstract}


protection of the environment. Public International Law faces the challenge of being within a delicate equilibrium between realism and idealism. The proposal of the Ecuadorian State to create the International Environmental Court is eminently idealistic

Key words: Nature, environment, ecocide, Public International Law, International Criminal Court, International Criminal Law.

\section{EM DIREÇÃO À CRIAÇÃO DO TRIBUNAL INTERNACIONAL DE JUSTIÇA AMBIENTAL}

\section{RESUMO}

A ideia central deste artigo gira em torno do Direito Internacional Público a partir de uma visão pragmática responde claramente a uma retórica para justificar ações políticas dos Estados, mas desde uma visão idealista também responde a conceitos mais abstratos, como encontrar a paz e a proteção ao meio ambiente. Em última análise, o Direito Internacional Público debate-se num delicado equilíbrio entre realismo e idealismo e a proposta do Estado Equatoriano de criação do Tribunal Internacional de Justiça Ambiental é uma proposta eminentemente idealista.

Palavras-chave: Natureza, ambiente, ecocídio, Direito Internacional Público, Tribunal Penal Internacional, Direito Penal Internacional.

\section{INTRODUCCIÓN}

El 30 de noviembre del 2015 durante la cumbre de clima París (COP 21) el presidente de Ecuador, Rafael Correa Delgado, a nombre del Estado ecuatoriano expresó la propuesta de nuestro país de crear la Corte Internacional de Justicia Ambiental para proteger los derechos de la naturaleza. $^{2}$

Las ideas fuerza en dicho discurso de planteamiento de la propuesta fueron las siguientes

"El papa Francisco, en su reciente encíclica Laudato Sí, nos recuerda que los países en vías de desarrollo están las más importantes reservas de la biósfera y que con ellas se siga alimentando el desarrollo de los países más ricos. Incluso es

2 Ver: Diario El Comercio Ecuador, 30 de noviembre del 2015, Correa propone crear Corte Ambiental. Disponible en http://www.elcomercio.com/tendencias/correa-propone-crear-corte-ambiental.html (sitio consultado 25 de julio del 2016). 
necesario ir más allá y realizar la Declaración Universal de los Derechos de la Naturaleza, como ya lo ha hecho Ecuador en su nueva Constitución. (...).

Aqui otra idea fuerza para evitar ciertos fundamentalismos: el ser humano no es lo único importante en la naturaleza, pero sigue siendo lo más importante.

La principal respuesta para la lucha del cambio climático es, entonces, crear la Corte Internacional de Justicia Ambiental la cual debería sancionar los atentados contra los derechos de la naturaleza y establecer las obligaciones en cuanto a deuda ecológica y consumo de bienes ambientales.

Nada, planeta entero escúchenme, nada justifica que tengamos tribunales para proteger inversiones, para obligar a pagar deuda financiera, pero no tengamos tribunales para proteger a la naturaleza y obligar a pagar las deudas ambientales. Se trata tan solo de la perversa lógica de privatizar los beneficios y socializar las pérdidas, pero el planeta ya no aguanta más" (La cursiva y negrita son nuestras). (Rafael correa en 21 conferencia del clima, COP21, 2015)

De inmediato el mundo entero empezó a discutir dicha propuesta. Ante los altos niveles de contaminación mundial, la necesidad de una justicia específica para proteger la naturaleza se hace cada vez más imperante. Muchos ahora la reclaman, desde los militantes ambientalistas hasta el Papa Francisco. La creación de una Corte Internacional especializada en defender el medio ambiente seguramente es una propuesta que muchos compartiríamos.

En este ensayo analizaremos en primer lugar, y como marco referencial, las principales motivaciones que sustentan el reconocimiento constitucional de los derechos de la naturaleza en el Ecuador y el constitucionalismo latinoamericano. En segundo lugar a la luz de las ideas preliminares para la creación de la Corte Penal Internacional analizaremos la propuesta de creación de la Corte Internacional de Justicia Ambiental.

\section{EL RECONOCIMIENTO CONSTITUCIONAL DE LOS DERECHOS DE LA NATURALEZA EN ECUADOR Y EN LATINOAMÉRICA}

Luego de la finalización del trabajo de la Asamblea Constituyente y la posterior ratificación del pueblo ecuatoriano a la Constitución de Montecristi, los derechos de la naturaleza fueron incorporados en el 
preámbulo y principalmente en los artículos 10 y 71 de la Constitución del Ecuador.

Para profundizar en las motivaciones que llevaron a los asambleístas constituyentes a realizar dicha incorporación, nos detenemos a analizar una de las actas de la Asamblea Constituyente que recoge uno de los debates:

El jusfilósofo Rudolph Von Ihering decía que el Derecho es "protección de intereses". Lo que nos preocupa y lleva a proteger a la Naturaleza, elevándola de objeto de protección jurídica a sujeto de derecho, es la necesidad de cambiar el paradigma de desarrollo, el enfoque de aproximación legal y la relación que el ser humano tiene con su entorno, a fin de evitar o, al menos, paliar las imprevisibles consecuencias que se producirán si mantenemos el sistema de depredación antropocéntrico. (Informe de Mayoría sobre los Derechos de la Naturaleza, 2008)

A la luz del texto constitucional ecuatoriano y de lo señalado en líneas anteriores, las ideas principales que giran en torno a dicho reconocimiento constitucional son: 1) el derecho protege intereses. E1 derecho entonces es una herramienta de protección; 2) la naturaleza pasa de ser objeto a ser sujeto del derecho en la búsqueda de un nuevo régimen de desarrollo (Cóndor \& Aguilera, 2010).

En la misma línea, creemos que el reconocimiento constitucional de los derechos de la naturaleza debe ser entendido a la luz de los cambios del constitucionalismo latinoamericano: de ahí que, por ejemplo, la Constitución de Bolivia de 2009 señala: "Cumpliendo con el mandato de nuestros pueblos, con la fortaleza de nuestra Pachamama y gracias a Dios refundamos Bolivia ${ }^{3}[\ldots]$ ". (preámbulo).

LaConstitución boliviana prescribe:

Las personas tienen derecho a un medio ambiente saludable, protegido y equilibrado. El ejercicio de este derecho debe permitir a los individuos y colectividades de las presentes y futuras generaciones además de otros seres vivos desarrollarse de manera normal y permanente. (art. 33) (la cursiva es nuestra)

De las referencias a la Constitución ecuatoriana y boliviana advertimos que, en primer lugar, el reconocimiento constitucional de los derechos de la naturaleza surge como respuesta a la atención de los daños

3 Además se debe destacar que Bolivia ha desarrollado los contenidos constitucionales en leyes específicas sobre el tema promulgando el 15 de octubre del 2012 la "Ley marco de la madre tierra y desarrollo integral para vivir bien" y el 21 de diciembre del 2010 la "Ley de Derechos de la madre tierra". 
ambientales producidos en el último siglo cuyas consecuencias han sido reclamadas en diferentes contextos ${ }^{4}$; en segundo lugar, dicha afirmación no se trata de una incorporación antojadiza y simbólica, de una ocurrencia vernácula, sino de una definición que emerge de la cultura tradicional del pueblo esencial a la idea moderna de la constitución ${ }^{5}$; por último, el nuevo constitucionalismo latinoamericano ${ }^{6}$ opta por proclamar una convivencia con todos los seres vivientes dentro de la Tierra denunciando coyunturalmente al fundamentalismo de mercado de las últimas décadas del siglo pasado, aunque desde una perspectiva mucho más amplia y universal. De este modo, la Pachamama ${ }^{7}$ se incorpora al desarrollo constitucional como otro aporte del constitucionalismo latinoamericano al universal (Zafarroni, 2011, pp. 107-108).

En definitiva, dotar de derechos a la naturaleza, para nosotros significa, alentar políticamente su paso de objeto a sujeto de derechos, como parte de un proceso centenario de ampliación de los sujetos del derecho, como recordaba ya en 1988 Jorg Leimbacher, jurista suizo:

Lo central de los derechos de la naturaleza, es rescatar el "derecho a la existencia" de los propios seres humanos (y por cierto de todos los seres vivos). Este es un punto medular de los derechos de la naturaleza, destacando una relación estructural y complementaria con los derechos humanos. (Citado por Acosta, 2012)

Consideramos que tiene sentido la incorporación constitucional de los derechos de la naturaleza en una Carta Magna como la ecuatoriana que reconoce un nuevo Régimen de Desarrollo ${ }^{8}$ sustentado en el

4 Entre la principal literatura sobre el tema puede consultarse: Lester R. Brown, El Estado del mundo, (México: s/e, 1988); D. J. Speddingo, Contaminación Atmosférica (Barcelona: s/e, 1981); Roger Garaudy, Ainda é tempo de viver, (Río de Janeiro: s/e, 1980); Ervin Laszlo, La última oportunidad, (Madrid: Círculo, 1985); Theodore Roszak, Persona/Planeta (Madrid: s/e, 1978), entre otros.

5 Ver: ZAFFARONI EUGENIO, (2011), "La Pachamama y el humano" en, Alberto Acosta y Esperanza Martínez, compiladores, La Naturaleza con derechos Ecuador, Abya -Yala, 111.

$6 \mathrm{Cfr}$. Al final de la última década, Bolivia y Ecuador fueron los dos países latinoamericanos que pasaron por transformaciones constitucionales más profundas en el curso de movilizaciones políticas protagonizadas por los movimientos indígenas. Producto de ello sus constituciones presentan conceptos de la filosofía andina, y se resalta el reconocimiento de los derechos de la Pachamama. DE SOUSA SANTOS BOAVENTURA, (2012) "Cuando los excluidos tienen derecho: justicia indígena, plurinacionalidad e interculturalidad", en Boaventura de Sousa Santos y Agustín Grijalva, editores, Justicia indígena, plurinacionalidad e interculturalidad en Ecuador, Ecuador, Fundación Rosa Luxemburg/Abya - Yala, 15.

7 La Pachamama es una deidad protectora, cuyo nombre proviene de las lenguas originarias y significa Tierra, en el sentido de mundo. Es la que todo da, pero como permanecemos en su interior como parte de ella, también exige reciprocidad (...) MERLINO RODOLFO, (s/a) "Pastores del Altiplano Andino meridional: religiosidad, territorio y equilibrio ecológico” Perú, Allpanchis,, 149-171.

8 Constitución del Ecuador, artículo 275. El modelo de desarrollo constitucional se basa en cinco principios. El primero, tratar al ser humano como sujeto y como fin. El segundo, es el equilibrio en la relación, sociedad, Estado y mercado. El tercero, es el de armonía con la naturaleza. El cuarto, el sumak kawsay. El quinto, economía social y solidaridad y plurinacionalidad. 
reconocimiento de un principio del Sumak Kawsay o Buen Vivir ${ }^{9}$, en el que tanto seres humanos como naturaleza somos parte de un todo. Es decir, el paradigma del Buen Vivir relaciona íntimamente lo social con lo ambiental, de tal forma que la Pachamama o la Madre Tierra mantenida y protegida, se convierte en requisito sine qua non para la existencia del sumak kawsay; en este contexto consideramos que era imperativo el reconocimiento jurídico de la naturaleza, además de ser una exigencia social (Cóndor y Aguilera, 2010).

Además, nos fundamentamos en la idea de que todo reconocimiento constitucional de derecho ha significado un proceso de lucha social (a veces de derramamiento de sangre) y que todo reconocimiento constitucional de derechos tiene otras implicaciones, aparte de las netamente jurídicas, es decir, nos acogemos a lo señalado por Stutzin (1984) en el sentido que el reconocimiento constitucional de los derechos de la naturaleza también implica efectos psicológicos, tal como ha sucedido cada vez que se ha ampliado el ámbito de los derechos humanos. De hecho creemos que el efecto psicológico del reconocimiento de dicho derecho constituirá una función educadora que conciba la personificación de la naturaleza como interlocutora válida del ser humano, y por ende conciba la presencia jurídica de la Pachamama como parte en los conflictos entre el hombre y medio ambiente, lo que favorecerá a su vez la búsqueda de la equidad ecológica en las relaciones del ser humano con el mundo natural.

Y concluimos este acápite haciendo nuestras las palabras de Eduardo Gudynas (2011), precursor de la incorporación constitucional ecuatoriana de los derechos de la naturaleza, cuando dice:

La cuestión clave es que el reconocimiento de los derechos de la Naturaleza abre las puertas para otro tipo de discusión en la política y la gestión, en la que ya no es necesario demostrar que preservar montañas o selvas es útil para el ser humano o rentable para las empresas. (p.100)

De ahí que en el ámbito nacional ecuatoriano esperamos que la elevación de la categoría jurídica de la naturaleza se traduzca en el mejoramiento de su condición social y, por consiguiente, en la adopción de políticas y normas de conducta que la favorezcan.

9 De acuerdo a la Constitución ecuatoriana el principio del sumak kawsay permite: primero, recuperar la armonía de la persona-comunidad y pacha mama o cosmos; segundo, impedir el modelo extractivista y depredador de los recursos naturales; $y$, tercero, que cualquier actividad de uso de la naturaleza esté limitado a que las generaciones futuras tengan también la posibilidad de usar y gozar en los mismo niveles la naturaleza. 


\section{IDEAS PRELIMINARES DE LA CREACIÓN DE LA CORTE INTERNACIONAL DE JUSTICIAAMBIENTAL}

De acuerdo al profesor Emiliano Buis "El Derecho sería, entonces, el sistema de normas jurídicas que regulan las relaciones que se dan entre quienes componen ese grupo humano, a los que el propio ordenamiento considerará sujetos (es decir, los centros de imputación de las normas, quienes podrán adquirir derechos o contraer obligaciones en el seno de dicho sistema). ${ }^{10}$

En la misma línea, consideramos que el Derecho es o debe ser expresión de la sociedad. No obstante, con frecuencia el ritmo social late tan deprisa que impide la producción de respuestas jurídicas inmediatas. En este marco, en el plano internacional, conseguir respuestas jurídicas a las realidades sociales mundiales es aún más difícil y lento. Y tal como lo señalan con acierto Isabel Lirola y Magdalena Martín"los obstáculos aumentan proporcionalmente a las implicaciones politicas del tema a tratar" (Lirola \& Martín, 2001).

No obstante en este trabajo partimos de la premisa del profesor Emiliano Buis (2015) que sostiene que:

El derecho internacional supone una narrativa y una retórica extremadamente útil para describir y justificar las acciones de los Estados y desde ese lugar pareciera no contraponerse sino reforzar la hegemonía imperial que históricamente ha signado las relaciones internacionales. Pero esta "concretitud" el hecho que responda a los intereses políticos y económicos de los actores del sistema internacional-es balanceada por una tendencia complementaria, una abstracción de "normatividad" que hace que el derecho internacional deba tener cierta impronta que lo convierta en una disciplina autónomo y se ocupe de ampliar sus contenidos sin recurrir de modo permanente a la realidad especifica de los intereses coyunturales de los Estados (...). Pareciera tratarse de visiones incompatibles en torno a la naturaleza del derecho internacional y; sin embargo, resultan perspectivas independientes. En el seno de esta naturaleza única, en un delicado equilibrio entre el realismo y el idealismo, se establece nuestra disciplina (la cursiva es nuestra).

Por lo tanto, basados en que existen ejemplos concretos en lo que la parte "idealista" del Derecho Internacional Público se ha materializado como

10 BUIS EMILIANO, "El Derecho Internacional Público: Concepto, características y evolución histórica", enhttp://www.academia.edu/13175698/_El_derecho_internacional_p\%C3\%BAblico_Concepto_caracter $\%$ C3\%ADsticas_y_evoluci\%C3\%B3n_thist $\overline{0} \% \mathrm{C} 3 \% \mathrm{~B} 3 \overline{\mathrm{r} i c a}$ _ (sitio consultado 10 de agosto del $201 \overline{6}$ ). 
en la creación de la Corte Penal Internacional sostenemos que la propuesta de la creación de la Corte Internacional de Justicia Ambiental también podría materializarse por cuanto se fundamenta en aspectos filosóficos absolutamente defendibles como la protección de los derechos de la naturaleza.

Con este contexto, en este ensayo nos basaremos en las ideas preliminares para la creación de la Corte Penal Internacional y analizaremos las principales y primeras críticas a la propuesta de creación de la Corte Internacional de Justicia Ambiental.

\subsection{El derecho internacional ambiental}

Las primeras voces críticas a la propuesta del Estado ecuatoriano han afirmado que con la misma "nos encontramos frente a una rara justicia ambiental ya que no se atenderían los impactos ambientales locales o nacionales, y estaría restringida a cuestiones planetarias" (Acción y Reacción, 2015).

Partimos de la idea que la creación y consolidación de la Corte Penal Internacional se da en parte por el genocidio yugoslaco (1991-1995) y ruandés (1994) y por el desarrollo alcanzado por el Derecho Internacional de los Derechos Humanos y por el Derecho Penal Internacional. ${ }^{12}$

En definitiva la creación de la Corte Penal Internacional concretiza la parte "idealista" del Derecho Internacional Público de proteger valores abstractos, en el caso concreto la paz, seguridad y bienestar de la humanidad.

Tal es así que el preámbulo del Estatuto de Roma (1998) textualmente señala:

Conscientes de que todos los pueblos están unidos por estrechos lazos y sus culturas configuran un patrimonio común y

\footnotetext{
11 Las primeras voces críticas a la propuesta, vienen de Ecuador y son de los grupos llamados “opositores" al gobierno de Rafael Correa o a su movimiento Revolución Ciudadana, principalmente del ex Presidente de la Asamblea Constituyente del Ecuador, Alberto Acosta, entre otros. La contradicción de la Corte Internacional de Justicia Ambiental. Disponible en http://accionyreaccion.com/la-contradiccion-de-la-corteinternacional-de-justicia-ambiental/(texto consultado el 27 de julio del 2016)

12 El surgimiento del Derecho Penal Internacional supone una importante evolución respecto del Derecho Internacional Clásico que era esencialmente interestatal y no consideraba a la persona como sujeto de Derecho Internacional. La responsabilidad individual es independiente de la responsabilidad internacional del Estado. AIZENSTATD LEISTENSCHNEIDER, NAJMAN ALEXANDER. (2012) La responsabilidad internacional de los Estados por actos ilícitos, crímenes internacionales y daños transfronterizos, México, Anuario Mexicano de Derecho Internacional 5.
} 
observando con preocupación que este delicado mosaico puede romperse en cualquier momento, Teniendo presente que, en este siglo, millones de niños, mujeres y hombres han sido víctimas de atrocidades que desafían la imaginación y conmueven profundamente la conciencia de la humanidad,' Reconociendo que esos graves crímenes constituyen una amenaza para la paz, la seguridady el bienestar de la humanidad, Afirmando que los crímenes más graves de trascendencia para la comunidad internacional en su conjunto no deben quedar sin castigo y que, a tal fin, hay que adoptar medidas en el plano nacional e intensificar la cooperación internacional para asegurar que sean efectivamente sometidos a la acción de la justicia. (la cursiva es nuestra).

Sobre el derecho penal internacional, los expertos en el tema señalan:

Esta disciplina responde a un doble proceso de internacionalización del derecho penal y de penalización del derecho internacional, que nos sitúa ante dos enfoques distintos: el del derecho penal y el del derecho internacional. El primero de ellos hace referencia a aquellos mecanismos y sistemas de cooperación interestatal a asegurar el cumplimiento de las legislaciones penales nacionales (...). El segundo se centra en la incorporación en el orden internacional de una serie de normas de naturaleza consuetudinaria incriminadoras de ciertos tipos de conductas cometidas por los individuos y para las que se prevé una sanción penal. (Delgado y Martínez, 2001)

Con este marco doctrinario y legal, consideramos que la creación de la Corte Internacional de Justicia Ambiental también motivará la creación y evaluación derecho internacional ambiental que obligatoriamente deberá encontrar un punto de convergencia entre el derecho ambiental nacional, que para nuestro criterio debería ser la protección de los derechos de la naturaleza.

Además, insistimos que la ciencia del Derecho Internacional Público busca también la protección de valores abstractos, como en el caso de la Corte Penal Internacional que buscó la protección de la paz, seguridad y bienestar de la humanidad. En esa misma línea, la Corte Internacional de Justicia Ambiental, y la rama del Derecho Internacional Ambiental buscarán también la protección de valores abstractos, como es la protección de los derechos de la naturaleza. 


\subsection{La promulgación de la Declaración Universal de los derechos de la Madre Tierra}

En la propuesta en estudio realizada por el Estado ecuatoriano se manifestó que "también es necesario caminar hacia una Declaración Universal de los Derechos de la Naturaleza para reforzar su llamado".

Ante lo cual señalamos que la Declaración Universal de los Derechos de la Naturaleza es promovida actualmente por el actual presidente de Bolivia, Evo Morales para la preservación popular del planeta Tierra.

Igualmente, fue parte de un proyecto parlamentario aprobado el 12 de octubre del 2012 como ley en Bolivia, que reconoce a la Tierra como un sistema viviente con derechos. Se acota que Morales exige a la Organización de las Naciones Unidas que otorgue el mismo valor a los derechos de la Tierra como a los derechos humanos. ${ }^{13}$

En lo referente a la Corte Penal Internacional señalamos que su creación fue el 17 de junio de 1998 en la Conferencia Diplomática de plenipotenciarios de las Naciones Unidas sobre el establecimiento de una Corte Penal Internacional, en la misma fecha también se ratificó el Estatuto de Roma ${ }^{14}$ catalogado como el instrumento constitutivo de la Corte Penal Internacional.

Por lo tanto, consideramos que resultaría idóneo que la comunidad internacional tenga la decisión de aprobar la Declaración Universal de los derechos de la Naturaleza que como lo analizamos en la primera parte de este ensayo consagra un nuevo paradigma en materia ambiental al definir a la naturaleza como sujeto de derechos. Este paradigma garantiza la tutela efectiva de la naturaleza y por ende del ser humano porque su propuesta se basa desde una visión biocéntrica ${ }^{15}$ que busca garantizar que los seres humanos y la naturaleza convivan armónicamente sin superioridades de ninguno; garantizando de esta forma el derecho a la existencia de ambos.

13 Derechos de la madre tierra. Disponible en https://cmpcc.wordpress.com/derechos-madre-tierra/ (sitio consultado el 25 de julio del 2016).

14 No podemos dejar de mencionar que el Estatuto de Roma hasta la actualidad no ha sido firmado ni ratificado, entre otros países, por Estados Unidos, Rusia, China, India, Israel, Cuba e Irak. Dato extraído del Estado de ratificación del Estatuto de Roma. Disponible en https://www.icrc.org/applic/ihl/ihl.nsf/ (sitio consultado el 26 de julio del 2016)

15 La doctrina biocéntrica que fundamenta el reconocimiento constitucional de los derechos de la naturaleza implica que aquella posee derechos que le son propios, y que son independientes de las valoraciones humanas, se da un paso mucho mayor. En síntesis, con dicha postura, la naturaleza pasa de ser objeto de derechos asignados por los humanos, a ser ella misma sujeto de derechos, y por lo tanto se admite que posee valores intrínsecos. GUDYNAS EDUARDO, (2012) El mandato ecológico: Derechos de la naturaleza y políticas ambientales en la nueva Constitución, Ecuador, Abya- Yala, 38. 


\subsection{La justiciabilidad del delito de "ecocidio"}

El profesor Juan Hernández, docente de Derecho de Empresa en la Universidad del País Vasco señala que

La propuesta del presidente Correa habla también de sancionar los atentados contra la naturaleza. ¿Cuál sería el crimen? De introducir la figura del 'ecocidio' entre los crímenes que juzga la Corte Penal Internacional hablan ciertos movimientos. Efectivamente, los crímenes internacionales que existen en este momento -el de lesa humanidad, el genocidio, la tortura- son tipificaciones insuficientes para un ejercicio económico tan agresivo. Somos cada vez los que planteamos si especular con los alimentos o el trabajo esclavo o la destrucción de entornos naturales que pueden llevar al aumento de las temperaturas y a la muerte de miles de personas deben entrar en un nuevo registro de crimen internacional. (América y economía, 2015)

Al respecto hay que señalar que a partir de 1970 ha existido un apoyo creciente por parte de varios gobiernos, empresas y comunidades para reformar el Estatuto de Roma y convertir el ecocidio en el quinto crimen contra la paz.

Para sus defensores el ecocidio hace referencia a cualquier daño masivo o destrucción ambiental de un territorio determinado de tal magnitud que ponga en peligro la supervivencia de los habitantes de dicho territorio. ${ }^{17}$ Además, el mismo es parte de un cuerpo emergente de leyes conocido como Jurisprudencia de la Tierra.

Los defensores de convertir el ecocidio en un crimen internacional argumentan que aquello es imperativo para proteger los derechos humanos y el medio ambiente. Sin embargo, sus oponentes argumentan que hacerlo criminalizaría al conjunto de la raza humana.

Por su parte en Ecuador, país en el que se reconoció constitucionalmente los derechos de la naturaleza, la norma penal (en adelante $\operatorname{COIP}^{18}$ )

16 Ver: London The University, Ecocide is the missing fifth crime against peace. 2012. Texto disponible http://www.sas.ac.uk/sites/default/files/files/hrc/Events\%20Documents/Ecocide\%20is\%20the\%20missing $\% 205$ th\%20Crime\%20Against \%20Peace.pdf( sitio consultado el 25 de julio del 2016).

17 Para los defensores del ecocidio la guerra de Vietnam es su origen como se desprende del libro del historiador norteamericano David Zierler The Invention of Ecocide: Agent Orange, Vietnam, and the Scientists Who Changed the Way We Think About the Environment (La invención del ecocidio, el agente naranja, Vietnam, y los científicos que cambiaron nuestra forma de pensar acerca del medio ambiente, University of Georgia Press, 2011)

18 COPI abreviatura de Código Orgánico Integral Penal ecuatoriano modificado integralmente en el año 2014 (norma sustantiva y adjetiva penal ecuatoriana). 
tipifica nuevos delitos contra el ambiente y la naturaleza. Entre ellos están los delitos contra la biodiversidad, contra los recursos naturales, contra la gestión ambiental y contra los recursos naturales no renovables.

No se incorpora expresamente el delito de ecocidio en la normativa penal ecuatoriana, sin embargo al ser una norma posterior a la Constitución que reconoce los derechos de la naturaleza resulta novedoso y adecuado también como el COIP regula la obligación de restauración y reparación de modo específico para los derechos de la naturaleza señalando lo siguiente:

Las sanciones previstas en este capítulo, se aplicarán concomitantemente con la obligación de restaurar integralmente los ecosistemas y la obligación de compensar, reparar e indemnizar a las personas y comunidades afectadas por los daños. Si el Estado asume dicha responsabilidad, a través de la Autoridad Ambiental Nacional, la repetirá contra la persona natural o jurídica que cause directa o indirectamente el daño. (COIP art. 257)

Sobre lo señalado en este acápite reconocemos que desde la década de los 70 la incorporación del delito de ecocidio ha resultado novedosa; no obstante hasta la presente fecha por falta de apoyo político no se ha materializado la propuesta de convertir al ecocidio en el quinto crimen contra la paz.

Ahora bien, consideramos que el reconocimiento del "ecocidio" junto con el reconocimiento y protección mundial a los derechos de la naturaleza no es una forma de criminalizar al conjunto de la raza humana por cuanto desde el fundamento de los derechos de la naturaleza (teoría biocéntrica) la defensa de la naturaleza es también la defensa de los seres humanos porque ambos formamos parte de un todo y como se señaló anteriormente, el fundamento de los derechos de la naturaleza es garantizar el derecho a la existencia de todos los seres vivos.

\section{CONSIDERACIONES FINALES}

En este trabajo se ha querido resaltar ideas preliminares de la propuesta del Estado ecuatoriano de crear la Corte Internacional de Justicia Ambiental a la luz de los nuevos paradigmas del constitucionalismo latinoamericano que reconoce a la naturaleza como sujetos de derechos y de las ideas preliminares de creación de la Corte Penal Internacional. Las conclusiones a las que llegamos son las siguientes: 
La Constitución de la República del Ecuador del 2008 reconoce un nuevo Régimen de Desarrollo sustentado en el reconocimiento de un principio del Buen Vivir en el que, tanto seres humanos como naturaleza somos parte de un todo. Es decir, reconoce el paradigma del Buen Vivir en el cual se relaciona íntimamente lo social con lo ambiental, de tal forma que la Pachamama o la Madre Tierra mantenida y protegida se convierte en requisito sine qua non para la existencia del sumakkawsay.

El nuevo modelo económico constitucional ecuatoriano planteado desde la cosmovisión de los pueblos indígenas y sustentado como a lo largo de la Constitución, está basado en el principio del sumak kawsay que permite: primero, recuperar la armonía de la persona-comunidad y pacha mama o cosmos; segundo, impedir el modelo extractivista y depredador de los recursos naturales; $y$, tercero, que cualquier actividad de uso de la naturaleza esté limitado a que las generaciones futuras tengan también la posibilidad de usar y gozar en los mismo niveles la naturaleza.

La Constitución ecuatoriana y boliviana consagran un nuevo paradigma en materia ambiental al definir a la naturaleza como sujeto de derechos. Al hacerlo rompen con los paradigmas del derecho tradicional clásico.

El Derecho Internacional Público a simple vista podría suponer tan solo una retórica para justificar las acciones políticas de los Estados; no obstante, también se debe considerar que el derecho internacional responde a concepciones más abstractas como la búsqueda de la paz, la seguridad, la conservación del medio ambiente; ejemplo de ello ha sido la propia creación de la Organización de Naciones Unidas (ONU) o la creación de la Corte Penal Internacional. Es decir, el Derecho Internacional Público sin lugar a dudas responde a aspectos sociológicos políticos pero también a lo largo de la historia ha respondido a aspectos filosóficos a favor de la humanidad.

En definitiva consideramos que el Derecho Internacional Público es una ciencia que se debate en un delicado equilibrio entre el realismo y el idealismo y precisamente la propuesta del Estado Ecuatoriano de creación de la Corte Internacional de Justicia Ambiental, es una propuesta idealista, fundamentada en el aspecto filosófico que contiene la concepción de los pueblos originarios de nuestra Latinoamérica, la protección de los derechos de la naturaleza que aspiramos algún día llegue a materializarse. 


\section{REFERENCIAS BIBLIOGRÁFICAS}

Acosta, A. (2012). Los derechos de la naturaleza, un lectura sobre el derecho a la existencia. En A, Acosta, \& E, Martínez (Eds.). La Naturaleza con derechos: De la filosofía a la política, Ecuador: Abya -Yala.

Aizenstatd, N. (2012) La responsabilidad internacional de los Estados por actos ilícitos, crímenes internacionales y daños transfronterizos. Anuario Mexicano de Derecho Internacional,1.

Asamblea Nacional Constituyente de Ecuador. (2008). Informe de Mayoría sobre los Derechos de la Naturaleza, Mesa No. 1 de Derechos Fundamentales y Garantías Constitucionales, Montecristi.

Buis, E. (2015). El Derecho Internacional Público: Concepto, características y evolución histórica. Recuperado de http://ww w.academia.edu/13175698/_El_derecho_internacional_p $\%$ C3\%B Ablico_Concepto_caracter\% $\% \bar{C} \overline{3} \%$ ADsticas_y_evoluci $\% \mathrm{C} 3 \% \mathrm{~B} 3 \mathrm{n}$ _hist $\% \overline{\mathrm{C}} 3 \%$ B3rica

Código Orgánico Integral Penal, Ecuador, 2014.

Cóndor, M., \& Aguilera, M. (2010). La iniciativa Yasuní ITT como materialización de los derechos de la naturaleza. Derechos Humanos y Derechos de la Naturaleza, 27. Recuperado de http://www.uasb. edu.ec/padh_contenido.php?cd=2967\&pagpath=1\&swpath=infb\&cd centro $=5 \& u g=$ puConstitución de la República de Ecuador [Const.] (2008).

Constitución Política de Bolivia [Const.] (2009).

Corte Penal Internacional. Estatuto de Roma. (17 de junio de 1998). Recuperado de http://www.un.org/spanish/law/ icc/statute/ spanish/rome_statute(s).pdf

Correa propone crear Corte Ambiental. (30 de noviembre del 2015). Diario El Comercio. Recuperado de http://www.elcomercio.com/ tendencias/correa-propone-crear-corte-ambiental.html

Declaración Universal de los Derechos de la madre tierra. Conferencia Mundial de los Pueblos sobre el Cambio Climático y los Derechos 
de la Madre Tierra. Recuperado de https://cmpcc.wordpress.com/ derechos-madre-tierra/

De Sousa Santos, B. (2012) "Cuando los excluidos tienen derecho: justicia indígena, plurinacionalidad e interculturalidad", en B. de Sousa Santos, \& A, Grijalva (Eds.). Justicia indígena, plurinacionalidad e interculturalidad en Ecuador. Ecuador: Fundación Rosa Luxemburg/Abya - Yala.

Ecocide is the missing fifth crime against peace. (2012). University of London. Recuperado de http://www.sas.ac.uk/sites/default/ files/files/hrc/Events\%20Documents/Ecocide\%20is\%20the $\% 20 \mathrm{~m}$ issing $\% 205$ th $\% 20$ Crime $\% 20$ Against $\% 20$ Peace.pdf

Ecuador y ¿la Corte Interamericana de Justicia Ambiental? (4 de diciembre de 2015). América economía. Recuperado de http://www.americaeconomia.com/politica-sociedad/politica/ ecuador-y-la-corte-internacional-de-justicia-ambiental

Estado de ratificación del Estatuto de Roma. (s.f). Recuperado de https://www.icrc.org/applic/ihl/ihl.nsf/

Gudynas, E. (2011). Los Derechos de la Naturaleza y la construcción de una justicia ambiental y ecológica en el Ecuador. Los Derechos de la naturaleza y la naturaleza de sus derechos, Ecuador: Ministerio de Justicia, Derechos Humanos y Cultos.

Gudynas, E. (2012) El mandato ecológico: Derechos de la naturaleza y políticas ambientales en la nueva Constitución, Ecuador: AbyaYala.

Ley 071. Ley de Derechos de la madre tierra. Gaceta Oficial del Estado plurinacional de Bolivia. Bolivia, 21 de diciembre del 2010.

Ley 300. Ley marco de la madre tierra y desarrollo integral para vivir bien. Gaceta Oficial del Estado plurinacional de Bolivia. Bolivia 15 de octubre del 2012.

Lirola, I., \& Martín, M. (2001) La Corte Penal Internacional (justicia versus impunidad). España: A\&M Gráfic. S.L.

Merlino, R. (2012) Pastores del Altiplano Andino meridional: religiosidad, territorio y equilibrio ecológico España:Allpanchis. 
Posel S. (2012). Ecocide the push to criminalize humanity for the sake of saving the planet. Rise Earth. Recuperado de http://www. riseearth.com/2012/11/ecocide-push-to-criminalize-humanity.html

Stutzin, G. (1984). Un imperativo ecológico: Reconocer los derechos de la naturaleza. AMB. y DES., 1 (1). 97-114. Recuperado de http://www.opsur.org.ar/blog/wp-content/uploads/2010/10/ imperativo-ecologico.pdf

Zaffaroni, E. (2011). La Pachamama y el humano. En A, Acosta \& E, Martínez (Comps.). La Naturaleza con derechos. Ecuador: Abya -Yala. 